\title{
Partnerships between health authorities and Amazon Alexa raise many possibilities - and just as many questions
}

- Cite as: CMAJ 2019 October 15;191:E1141-2. doi: 10.1503/cmaj.1095799

Posted on cmajnews.com on Sept. 24, 2019

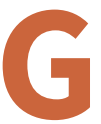
oodbye keyboard; hello Alexa. Under a recent partnership between the United Kingdom's National Health Service (NHS) and Amazon, the company's voice-activated assistant is standing by to answer citizens' health questions.

Wonder if that rash might be chickenpox? Ask Alexa. How should you treat your sprained ankle? Alexa can answer that, too, with Amazon's algorithm accessing information from the NHS website to provide medical advice to UK residents.

In Canada, Alberta Health Services (AHS) allows people to ask Alexa and Google Home devices for daily wellness tips on topics such as nutrition, exercise and injury prevention. The devices can also provide AHS news, real-time estimated wait times for AHS emergency

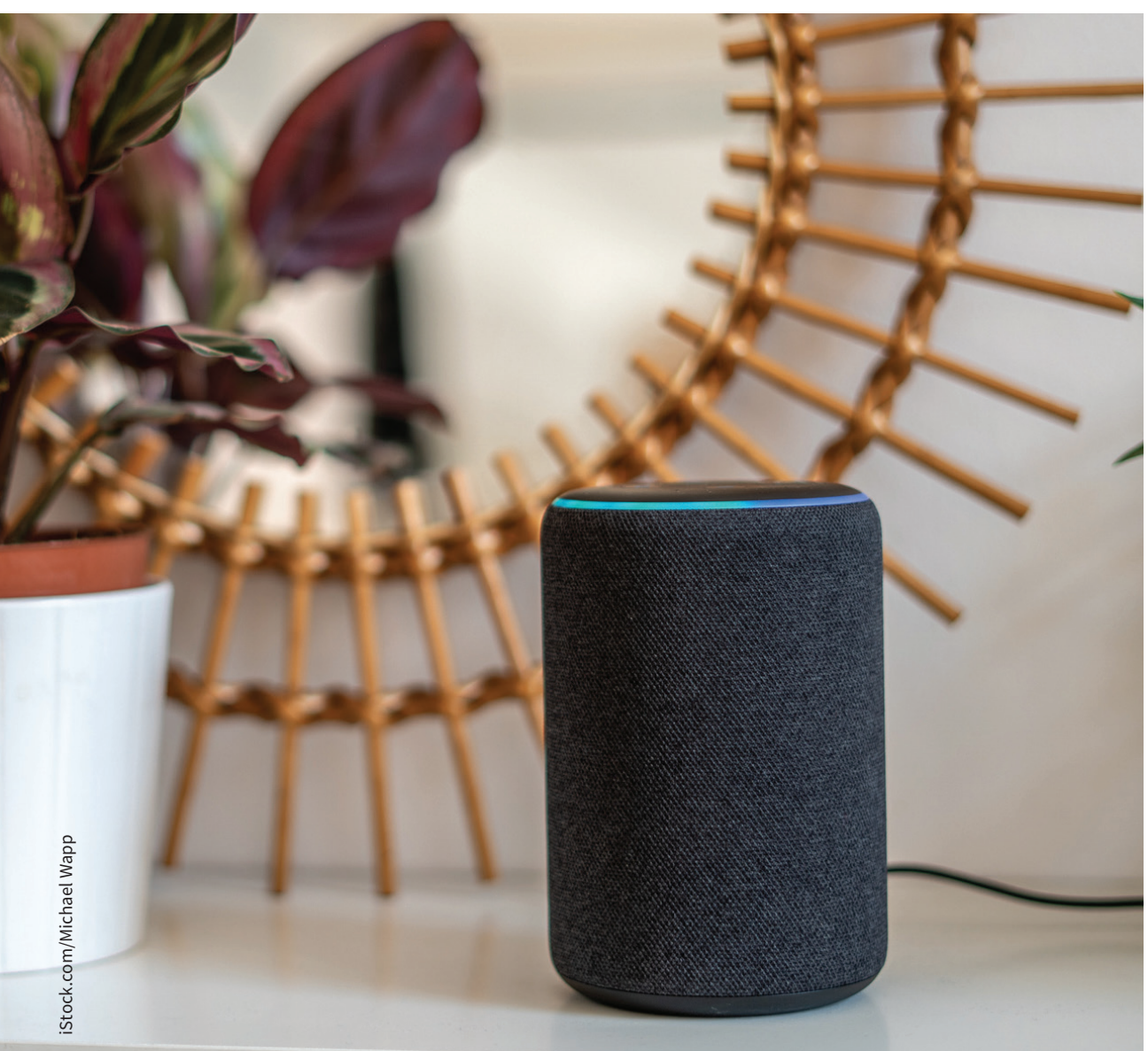

UK residents can use Amazon Alexa to access medical advice from the website of the National Health Service. departments, and information about influenza immunization clinics. The AHS claims to be "the first public health care organization in Canada to offer health care information on the Google and Amazon devices."

But as health authorities turn to voiceactivated technology to inform patients and ease pressure on overburdened health care systems, skeptics are wondering how data-driven companies like Amazon might someday exploit the medical information users are sharing.

Dr. Teri Fisher is bullish on the future of voice technology, calling the NHS announcement a step toward a "voicefirst future" in which interactions with digital assistants like Alexa will be seamless, the devices acting as personal navigators to the health care system. A clinical assistant professor at the University of British Columbia, he combines his passions for health care and technology through two voice-technology podcasts: Voice First Health and Alexa in Canada.

"I can see a time when your device will help determine the urgency of your medical problem, essentially acting like a triage nurse that guides you through multiple steps in the health care system," he said. Older people and the young are early adopters of voice technology, but Fisher believes it's only a matter of time until it revolutionizes how a much wider swath of the population experiences health care. He likens the current excitement around voice tech to what happened in the early days of the iPhone, when developing apps was all the rage. "Everyone wanted to create the next best app; it started with simple things like 
flashlight apps, but that soon led to apps that changed the way we use technology - think Instagram and Uber."

Cybersecurity experts, however, have been quick to raise potential privacy and security concerns. "The nature of this info is incredibly private, incredibly personal. We don't entirely know how Amazon is going to use it in the future," warned Stephanie MacLellan, a cybersecurity and digital policy analyst who is a fellow with Canada's Public Policy Forum. "Amazon can say right now that they're not using the information gathered through Alexa to profile its customers, but down the road that could change."

She noted that Amazon is a data-driven company and the medical information of millions of Alexa users is a potential goldmine for insurance and pharmaceutical companies. Unless privacy laws are updated to address the unanticipated uses of medical information in the digital age, MacLellan said, people should understand the possibility that anything they say to a digital assistant could remain on a company's servers indefinitely.

"If there are ways Canada could deliver this type of service without partnering with a private international company, I would look at those first," she said.

Fisher agrees that privacy must be protected, but posits that privacy concerns are generational, with younger users willing to trade some privacy for the sake of convenience. He is looking forward to a future in which artificial intelligence and voice technology streamline the health care system's ability to provide the right care at the right time in the right place.

"Our smart devices will be patientcentred. They'll be able to tell us what care we need, when to access it, and where to go, whether that be to a family doctor, the pharmacy or the emergency room," he said. They'll act as virtual mini-clinics, ordering our medication, having it delivered, and calling in sick to our workplace, he added. "Granted there will need to be regulations in place, but I believe that younger generations are inclined to use the technologies and prepared to put up with risks."

Sarah Brown, Ottawa, Ont. 